\title{
Closest conjunct agreement in replacives: Experimental evidence from Estonian
}

\author{
Marju Kaps*
}

\begin{abstract}
The phenomenon of closest conjunct agreement (CCA) has been documented cross-linguistically in conjunctions ("X and $\mathrm{Y}$ ") and disjunctions ("(either) $\mathrm{X}$ or $\mathrm{Y}$ "), and agreement patterns with feature-mismatching coordination have been shown to be variable, both across constructions and speakers. The present work addresses agreement patterns with replacives subjects ("not X but Y") in Estonian, where subjects can occur pre- or postverbally. Replacives differ from other forms of coordination by having a single asserted subject. A series of two speeded acceptability experiments with postverbal subject replacives, and a relative naturalness rating experiment comparing replacives to disjunctions showed that both CCA and a bias towards agreeing with the asserted subject (ASA) play a role in determining verbal agreement with replacive subjects. Additionally, there is evidence for less featurally marked 3rd person verb forms being preferred, particularly when there are conflicting pressures on agreement from CCA and ASA, and for person mismatches being fully repaired by morphological syncretism.
\end{abstract}

Keywords. verbal agreement; closest conjunct agreement; replacives; disjunction; Estonian

1. Introduction. Closest conjunct agreement (CCA) has been of long theoretical interest to syntacticians (e.g. Koutsoudas 1968, Corbett 1983; see Nevins \& Weisser 2019 for a recent review). In instances where a verb is not able to agree with both conjuncts in a coordinate phrase in its overt morphological form, such as the English example in (1), CCA is seen when the verb preferentially agrees with the conjunct linearly closest to it.

\section{(1) Either John or I $\{$ ?am / *is $\}$ leaving.}

While CCA appears to be fully grammatical in some languages and constructions (e.g. conjunctions with mismatching object gender in Hindi-Urdu, Bhatt \& Walkow 2011), in others it appears to act as a repair mechanism when the speaker is confronted with an utterance they would normally take measures to avoid. Foppolo \& Staub (2020) argue based on experimental evidence from English and Italian that agreement with disjunctive subjects of mismatching grammatical features is 'a grammatical lacuna or gap' in the sense that any relevant rules of agreement are not strictly enforced by the grammar. To some extent, this indeterminacy can be attributed to a lack of input - when a paraphrase such as 'Either John is leaving or I am leaving' for (1) is available, speakers can avoid the feature mismatch between the verb and one of the conjuncts. Agreement patterns with conjuncts mismatching in their person, number or gender features thus provide a window to grammatical preferences in cases of impoverished input.

Previous work has looked at CCA in conjunctions ("X and Y"), and to some extent disjunctions ("(either) $\mathrm{X}$ or $\mathrm{Y}$ "). There is an interesting semantic contrast between conjunctions and disjunctions, whereby in conjunctions both conjuncts are asserted and in disjunctions neither is. In this paper, I look at a third construction, replacives ("not X but Y"), in which only

\footnotetext{
${ }^{*}$ I would like to thank Carson Schütze for helpful discussion and insights, as well as Jesse Harris, Tim Hunter, Stefan Keine and Hilda Koopman for their feedback at earlier stages of this project. Experiments 1 and 2 were conducted at the Institute of Estonian and General Linguistics at the University of Tartu. Author: Marju Kaps, University of California, Los Angeles (mkaps@ucla.edu).
} 
the second conjunct is asserted, allowing us to pull apart and examine any independent effects that CCA and asserted subject agreement may have in cases of featural mismatch. I am here assuming a coordination analysis for replacives, akin to constituent conjunctions and disjunctions (but see e.g. Fehrmann 2008 for a discussion of the syntax of contrastive coordination).

Estonian has a clause-final focus position (Henk 2010), which allows for focused subjects, including replacive subjects to follow the verb. In (2), the 1st person singular closest conjunct (CC) is also the asserted subject (AS) and 1st person singular marking on the verb is considered quite natural. A more interesting pattern is seen in (3), where the 3rd person singular subject is the CC but the 1st person singular subject is the AS. In this case, CCA might be preferred, but is not judged to be fully grammatical. Notably, unlike conjunctions and disjunctions, plural agreement is not grammatically available as a rescue strategy in replacives.

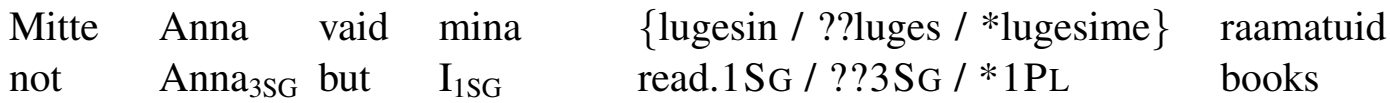

'Not Anna but I was reading books.'

$\begin{array}{lllll}\text { Raamatuid } & \{\text { ?luges / ??lugesin / *lugesime }\} & \text { mitte } & \text { Anna vaid } & \text { mina } \\ \text { books } & \text { read.?3SG / ??1SG / *1PL } & \text { not } & \text { Anna }_{3 \mathrm{SG}} \text { but } & \mathrm{I}_{1 \mathrm{SG}}\end{array}$

'Not Anna but I was reading books.'

In contrast with the feature mismatching postverbal replacive (3), where grammaticality appears to be degraded as the verb cannot agree with both the CC and the AS, we see in (4) that this subject-final construction is fully grammatical with two 3rd person subjects and 3rd person singular verbal agreement.

$\begin{array}{lllll}\text { Raamatuid } & \text { \{luges } / * \text { lugesid }\} & \text { mitte } & \text { Anna vaid } & \text { Mari } \\ \text { books } & \text { read.3SG } / * 3 \mathrm{PL} & \text { not } & \text { Anna }_{3 \mathrm{SG}} \text { but } & \text { Mari } 3 \mathrm{SG} \\ \text { 'Not Anna but Mari was reading books.' } & & \end{array}$

Additionally, as shown in (5), Estonian allows for negative concord ${ }^{1}$ with postverbal replacives. A participle form of the verb is used with the negative particle 'ei', meaning that the verb does not exhibit person features. This morphological syncretism appears to repair agreement mismatches in replacives, similarly to what has been reported for conjuctions (e.g. Bhatt \& Walkow 2013).

$\begin{array}{lllllll}\text { Raamatuid } & \text { ei } & \text { lugenud } & \text { mitte } & \text { Anna vaid mina } \\ \text { books } & \text { NEG } & \text { read.PTCP } & \text { not } & \text { Anna }_{3 S G} \text { but } & \mathrm{I}_{1 \mathrm{SG}}\end{array}$

'Not Anna but I was reading books.'

The present work focuses on person feature mismatches in subject agreement, as Estonian verbs do not agree with objects and gender is not grammatically marked. In the following, I present evidence from three experiments - two speeded acceptability experiments looking at postverbal replacives with different agreement patterns, and a relative naturalness judgment experiment comparing agreement preferences in preverbal and postverbal replacives with disjunctions, which lack an AS.

\footnotetext{
${ }^{1}$ An additional double negation reading is available when the negative particle 'ei' is stressed.
} 


\section{Experiment 1.}

2.1 Motivation. The aim of this experiment was to empirically investigate the intuition that person mismatches in replacives are degraded in Estonian, but repaired by morphological syncretism ( $c f$. Bhatt \& Walkow 2011). That is, the source of the reduced grammaticality in these constructions lies in verbal agreement, rather than a dispreference for coordinating two subjects with different person marking.

2.2 PARTICIPANTS. 44 native Estonian speaker volunteers were recruited from the University of Tartu and the surrounding community. An additional 2 participants' data were excluded from the analysis as described below. Participants received 5 EUR for the 40-minute experiment.

2.3 MATERIAls AND METHOD. A speeded grammaticality task was chosen for this experiment, with rapid serial visual presentation (RSVP) of $200 \mathrm{~ms}$ per word and a $50 \mathrm{~ms}$ inter-stimulus interval, which most participants judged to be a natural reading pace during post-experiment interviews. Participants were instructed to respond "YES" or "NO" to a grammaticality judgment as quickly and accurately as possible at sentence offset using a button press. Half of the items were additionally followed by a comprehension question in order to encourage natural reading of the material. The Linger software (Rohde 2003) was used for presentation and response collection and guided training was provided to familiarize participants with the procedure.

A sample item for the experiment is shown in Table 1. 24 experimental items crossed Subject person (Match, Mismatch) with Verb form (Positive, Negative). Person match items contained two 3rd person conjuncts, while mismatch items contained a 3rd person conjunct and a 1st person conjunct. The person mismatch became apparent only on the last word of the sentence (i.e. the AS), allowing the participants' immediate response to agreement mismatches to be captured at sentence offset. Experimental items were presented in a Latin Square design along with 64 filler items from unrelated experiments and 20 catch items, with roughly $50 \%$ of all sentences a participant saw estimated to be ungrammatical or severely marginal. Trial order was randomized on a by-participant basis.

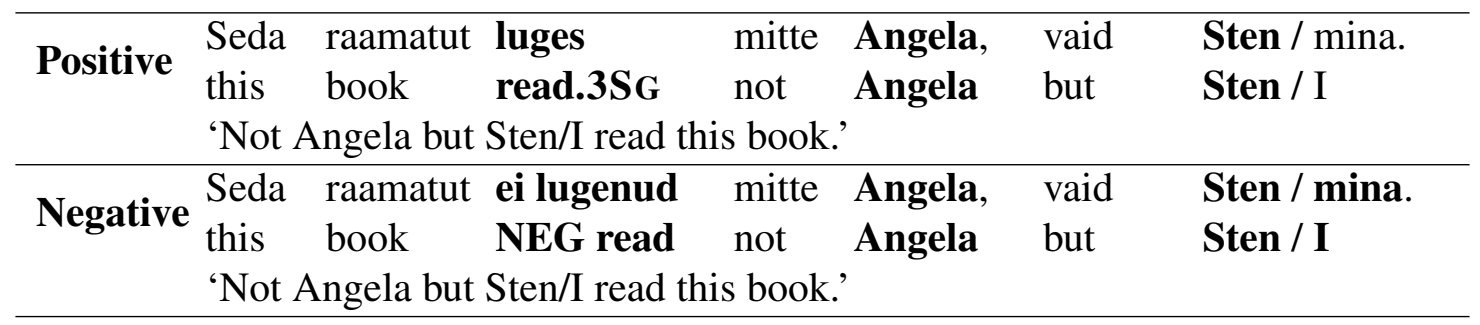

Table 1. Sample item for Experiment 1. Subjects agreeing with the verb are bolded.

2.4 Results AND Discussion. One participant's data were excluded from the analysis due to a below $80 \%$ accuracy on grammaticality judgments to the catch items, and one participant's data for counterbalancing reasons.

By-condition acceptance rates are plotted in Figure 1. The data were analyzed in binomial glmer models in R (Team 2013), crossing Person and Verb, with random intercepts for participants and items. The model was subjected to pairwise comparisons with tukey adjustments in 
the emmeans package, revealing that the Positive Person Mismatch significantly differed from all other conditions $(p s<.001)$, with no other significant effects. Allowing for a certain amount of error due to the speeded nature of the task, acceptance rates are at ceiling for both of the negative concord conditions, as well as the inflected verb condition with two 3rd person subjects.

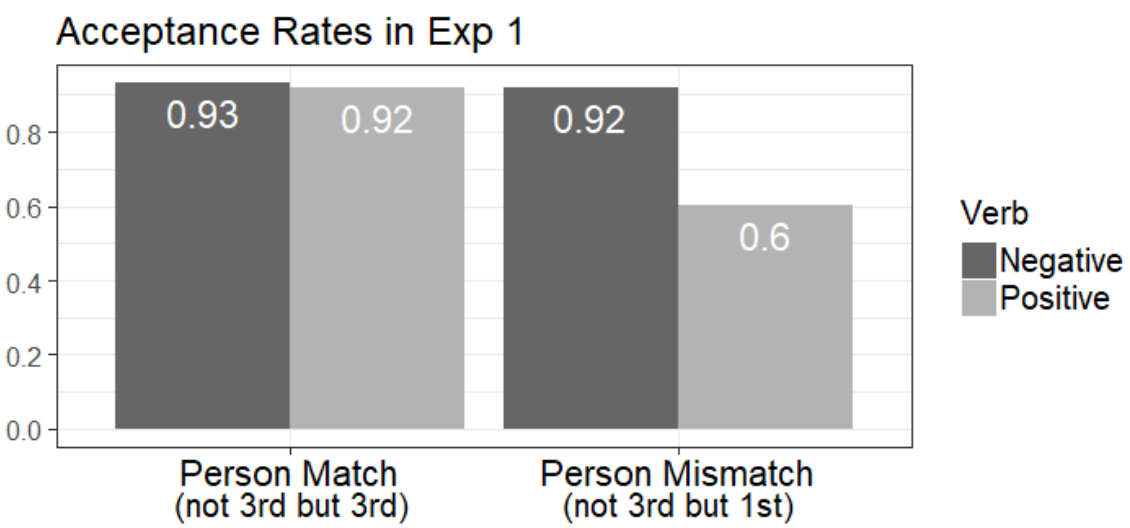

Figure 1. Acceptance rates in Experiment 1

The results point to a penalty when the two subjects in a replacive construction differ in their person features but the verb only agrees with one of the conjuncts. Person mismatches are fully repaired by morphological syncretism, in this case the participle form used in sentential negation in Estonian. Interestingly, while the acceptability of postverbal replacives decreases in the case of agreement mismatches, these sentences are still judged to be acceptable at a rate of $60 \%$ overall. A look at by-participant data reveals considerable variability in responses $-16 \%$ of the participants categorically rejected the Person mismatch Positive verb condition, $36 \%$ always accepted these sentences as grammatical, and the remaining $48 \%$ fell somewhere in between. These figures may represent task-specific strategies, or more interestingly, variability in individual grammars in the absence of relevant input (since speakers can resort to syncretic negative concord in cases of featural mismatches in replacives).

\section{Experiment 2.}

3.1. Motivation. The goals of this follow-up experiment were multi-fold. Firstly, since only CCA was tested in Exp 1, and not ASA, I wanted to rule out the possibility that the reduction in grammaticality arose from agreement with the wrong conjunct. Secondly, in Exp 1, the closest conjunct was always 3rd person, however prior research (e.g. Coon et al. 2017) points to featural hierarchy effects in agreement. With 1st person [+speaker, +participant] being more featurally marked than 3rd person [-speaker, -participant], we might expect to see a preference for the less marked 3rd person form overall, akin to languages where the default masculine gender is used to agree with conjuncts mismatching in gender features (e.g. Hindi, Bhatt \& Walkow 2011).

Additionally, a comparison with constructions with two overt verbs was conducted in order to address a potential syntactic argument that the appearance of CCA in postverbal replacives arises from the (matrix) verb underlyingly agreeing with its local subject rather than the full conjunct, and the non-local subject agreeing with an elided verb. Thus, rather than in- 
volving constituent coordination, replacives might instead arise from a coordination of larger constituents. If the reduced grammaticality of feature-mismatching replacives arises from the second conjunct not having an overt verb to agree with (or perhaps a condition of identity on ellipsis), we would expect to see at-ceiling acceptance in a double verb baseline condition.

3.2. PARTICIPANTS. A smaller sample of 14 native Estonian speaker volunteers were recruited from the University of Tartu and the surrounding community, as in Exp 1. One additional participant's data were excluded from the analysis due to them rejecting less than $80 \%$ of the ungrammatical catch items. Participants received 5 EUR for the 40-minute experiment.

3.3. MATERIALS AND METHOD. The method was identical to Exp 1. A sample item (modified from Exp 1) is shown in Table 2, showing the six conditions arising from crossing Conjunct order (with the second conjunct always being the AS) with Agreement (a Double Verb baseline, CCA and ASA). All conditions contained a person mismatch between the two subject conjuncts. The 30 experimental items were presented in a Latin Square design with 80 fillers from unrelated experiments and 20 ungrammatical catch items, with half of all sentences estimated to be ungrammatical or severely marginal.

\begin{tabular}{|c|c|c|c|c|c|c|c|}
\hline Conjunct Order & Agreement & Seda raam & itut... & & & & \\
\hline \multirow{3}{*}{$\begin{array}{l}\text { not 1st but 3rd } \\
\text { 'Not I but Sten } \\
\text { read this book.' }\end{array}$} & Double Verb & $\begin{array}{l}\text {..lugesin } \\
\text { read.1SG }\end{array}$ & $\begin{array}{l}\text { mitte } \\
\text { not }\end{array}$ & $\begin{array}{l}\text { mina, } \\
\text { I }\end{array}$ & $\begin{array}{l}\text { vaid } \\
\text { but }\end{array}$ & $\begin{array}{l}\text { luges } \\
\text { read.3SG }\end{array}$ & $\begin{array}{l}\text { Sten. } \\
\text { Sten }\end{array}$ \\
\hline & CCA & $\begin{array}{l}\text {...lugesin } \\
\text { read.1SG }\end{array}$ & $\begin{array}{l}\text { mitte } \\
\text { not }\end{array}$ & $\begin{array}{l}\text { mina, } \\
\text { I }\end{array}$ & $\begin{array}{l}\text { vaid } \\
\text { but }\end{array}$ & & $\begin{array}{l}\text { Sten. } \\
\text { Sten }\end{array}$ \\
\hline & $\mathbf{A S A}$ & $\begin{array}{l}\text {...luges } \\
\text { read.3SG }\end{array}$ & $\begin{array}{l}\text { mitte } \\
\text { not }\end{array}$ & $\begin{array}{l}\text { mina, } \\
\text { I }\end{array}$ & $\begin{array}{l}\text { vaid } \\
\text { but }\end{array}$ & & $\begin{array}{l}\text { Sten. } \\
\text { Sten }\end{array}$ \\
\hline \multirow{3}{*}{$\begin{array}{l}\text { not 3rd but 1st } \\
\text { 'Not Sten but I } \\
\text { read this book' }\end{array}$} & Double Verb & $\begin{array}{l}\text {...luges } \\
\text { read.3SG }\end{array}$ & $\begin{array}{l}\text { mitte } \\
\text { not }\end{array}$ & $\begin{array}{l}\text { Sten, } \\
\text { Sten }\end{array}$ & $\begin{array}{l}\text { vaid } \\
\text { but }\end{array}$ & $\begin{array}{l}\text { lugesin } \\
\text { read.1SG }\end{array}$ & $\begin{array}{l}\text { mina. } \\
\text { I }\end{array}$ \\
\hline & CCA & $\begin{array}{l}\text {...luges } \\
\text { read.3SG }\end{array}$ & $\begin{array}{l}\text { mitte } \\
\text { not }\end{array}$ & $\begin{array}{l}\text { Sten, } \\
\text { Sten }\end{array}$ & $\begin{array}{l}\text { vaid } \\
\text { but }\end{array}$ & & $\begin{array}{l}\text { mina. } \\
\text { I }\end{array}$ \\
\hline & $\mathbf{A S A}$ & $\begin{array}{l}\text {..lugesin } \\
\text { read.1SG }\end{array}$ & $\begin{array}{l}\text { mitte } \\
\text { not }\end{array}$ & $\begin{array}{l}\text { Sten, } \\
\text { Sten }\end{array}$ & $\begin{array}{l}\text { vaid } \\
\text { but }\end{array}$ & & $\begin{array}{l}\text { mina. } \\
\text { I }\end{array}$ \\
\hline
\end{tabular}

Table 2. Sample item for Experiment 2

\subsection{RESULTS AND DISCUSSION. The by-condition acceptance rates are plotted in Figure 2. A} binomial glmer model crossing Conjunct order and Agreement type as fixed effects, with random intercepts for participants and items showed a penalty for ASA conditions $(\mathrm{M}=0.25$, $\mathrm{SE}=0.04)$ compared to the Double Verb baseline $(\mathrm{M}=0.66, \mathrm{SE}=0.04), p<.001$. There was no such penalty for the CCA conditions $(\mathrm{M}=0.64, \mathrm{SE}=0.04), p=.714$. Additionally, there was a significant interaction between Conjunct order and Agreement type $p<.05$, as "not 3rd but 1st" order was penalized in ASA conditions but not in the other agreement conditions. This confirms that 3rd person matrix verbs were overall associated with higher rates of acceptance $(\mathrm{M}=0.58)$ than 1 st person matrix verbs $(\mathrm{M}=0.46)$.

Overall, these results indicate that CCA improves the acceptability of replacives with mismatching subject person features, compared to agreement with the non-closest AS conjunct. This is an interesting finding, suggesting that linear order is a stronger determinant of agree- 


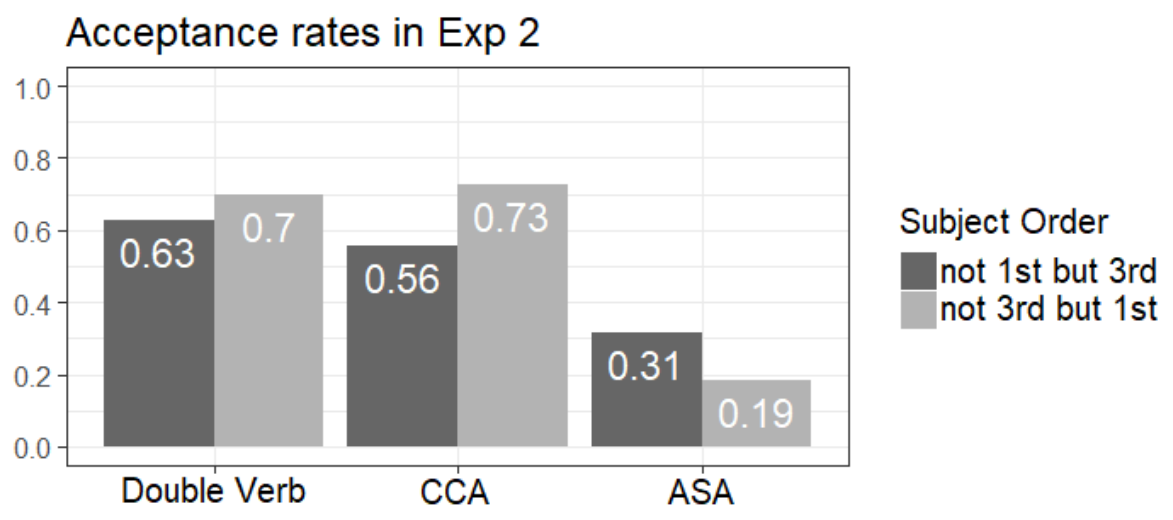

Figure 2. Acceptance rates in Experiment 2

ment preferences than interpretation, at least when it comes to speeded acceptability judgments. It is possible that a different paradigm allowing the comprehender more time to arrive at the intended interpretation and to resolve the semantic dependency between the verb and the asserted subject could yield a different pattern of results.

Secondly, we see that less featurally marked 3rd person verb forms ([-speaker, -participant]) are preferred over more marked 1 st person verb forms ([+speaker, +participant)] when the verb cannot agree with both subjects in its surface form. The preference for unmarked features, regardless of the order of the conjuncts, points to the possibility of resolved agreement, whereby the verb agrees with the full replacive by exhibiting unmarked features or features shared between the two conjuncts. In this particular case, we see singular verb forms, although plural forms have previously been found to be used with singular subject conjunctions (Bhatt \& Walkow 2011).

Interestingly, the double verb conditions pattern similarly to the CCA conditions, showing that there is no advantage to an overt verb agreeing with the local subject in the second conjunct. This points to the reduction in grammaticality in replacives with mismatching subject features arising from the form of the verb in the matrix clause (compare to at-ceiling acceptance for syncretic forms with mismatching subjects in Exp 1), rather than the second conjunct (i.e. the asserted subject) not being licensed by an agreeing verb. This observation provides further support for a coordination analysis for replacives, whereby the matrix verb licenses both subject conjuncts, rather than the second conjunct containing an elided verb that agrees with the second subject locally.

\section{Experiment 3.}

4.1. Motivation. So far, we have seen that postverbal replacives with mismatching person features with CCA show diminished grammaticality (Exp 1), but that the same constructions with ASA are even more degraded (Exp 2). Exp 2 also provided evidence for a preference for less featurally marked 3rd person verb forms over 1st person verb forms, suggesting that conjunct order and interpretation are not the sole determinants of agreement.

The aim of this final experiment was to compare replacives directly to disjunctions, looking at both postverbal and preverbal subject constructions. There are multiple comparisons of interest here. Firstly, since the CC and the AS coincide in preverbal (subject-verb, SV) re- 
placives, but differ in postverbal (verb-subject, VS) replacives, comparing the two constructions allows for an assessment of the relative strength of CCA and ASA. Secondly, since disjunction does not involve an AS, we can observe the independent effect of ASA by comparing replacives and disjunctions. Thirdly, by manipulating conjunct order, we can examine the relative contribution of featural markedness across different constructions.

A relative naturalness rating task was chosen instead of a more traditional fill-in-the-blank task or a binary forced choice task in order to obtain more fine-grained information about the relative naturalness of verbal forms in these constructions.

4.2. PARTICIPANTS. 40 native Estonian speaker volunteers were recruited via social media. An additional 12 participants' data were excluded from the analysis as described below.

4.3. MATERIALS AND METHOD. The relative naturalness task was conducted over the Internet, on the Ibex Farm platform (Drummond 2013). All sentences included a blank, with two inflectional forms of the omitted lexical item presented below it, placed at opposite ends of a sliding scale, as seen in Figure 3. Participants were instructed to move the position of the slider from its initial central position to be in proportion with the relative naturalness of the two word forms in the blank. The experiment began with a few guided practice trials.

Taksoga tookord ainsana mitte mina vaid Anneli.

sõitis

sõitsin

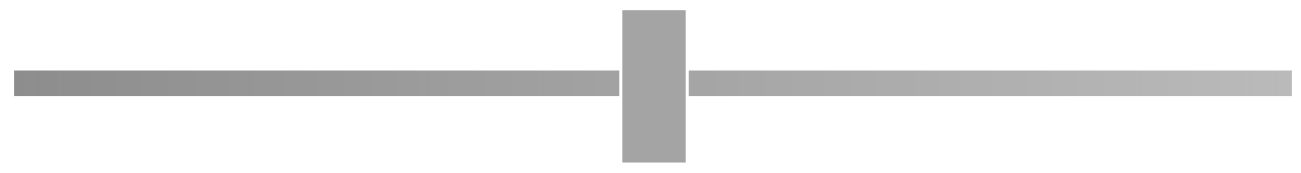

Figure 3. A display of a trial in Experiment 3

Participants saw 24 experimental items (crossing Word order and Construction type, as shown in Table 3), along with 40 fillers and 10 catch items in a Latin Square design. Presentation order was randomized on a by-participant basis. The filler items involved two nominal or verbal forms that were both grammatical in the blank but varied in their relative naturalness or plausibility. The catch items involved a grammatical and an ungrammatical form. The person of the CC (1st or 3rd) was kept constant across the four experimental conditions in each quadruplet, but varied orthogonally between items. The sample item contains a 1 st person $\mathrm{CC}$. The order of presentation of target forms (i.e. whether the 1st or 3rd person form appeared to the left) was counterbalanced across items, to ensure the form that participants saw first did not systematically bias the results.

All target forms were 1st and 3rd person forms of a singular verb. While disjunctions with a 1st and 3rd person subject allow for 1st person plural agreement on the verb, this option is not grammatically available for replacives in Estonian. Thus, singular forms were used throughout the experiment in order to directly compare the two constructions.

Additionally, I was interested in potential effects of surface form markedness (see Pul- 


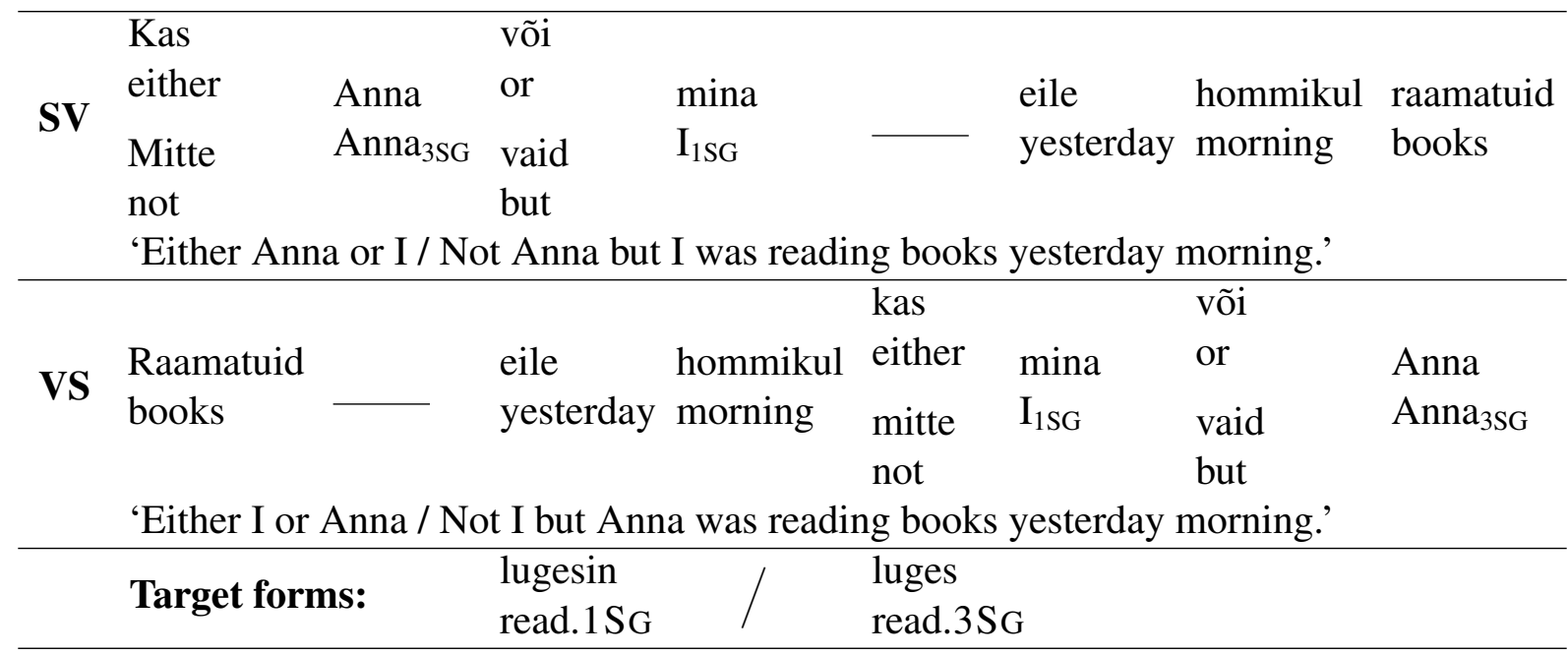

Table 3. Sample item for Experiment 3

lum \& Zwicky 1986 for evidence of phonological repair of agreement mismatches). Therefore, in half of the items the 1st person form (e.g. luges +in 'read.1SG') was built transparently on the 3rd person form (luges 'read.3SG'), while the other half involved vowel deletion from the 3rd person form (e.g. sõitis 'ride.3SG') to build the 1 st person form (sõit_s+in 'ride.1SG'). ${ }^{2} \mathrm{I}$ hypothesized that the 3rd person forms acting as unaltered stems for the formation of the $1 \mathrm{st}$ person form were less marked for 3rd person and more root-like, and might be preferred over 1 st person forms at higher rates than 3rd person forms undergoing vowel deletion.

4.4. RESUlTS AND DISCUSSION. The position of the slider on each trial was recorded as a numerical value between 0 and 100 for the two word forms, with 1-point increments. Catch items were coded with the correct word form corresponding to 100; ten participants' data were excluded from the analysis due to an average score below 95 on the catch items in order to ensure that participants were paying attention to the experiment and understood how to use the slider. One participant's data were excluded due to self-reported non-native speaker status. One further participant was removed for counterbalancing reasons, meaning that every experimental item was seen by ten participants in each of the four experimental conditions.

For ease of interpretation, the scores were converted to bias scores ranging from -50 to +50 , with 0 indicating a central position on the scale. Firstly, it was of interest whether 1 st or 3rd person verb forms were preferred overall, and whether verb form (undergoing stem alernations or not) affected the naturalness of the 3rd person forms. Table 4 shows 3 rd person bias scores by condition. The highest 3rd person bias is seen in VS replacives (the condition where the $\mathrm{CC}$ and the AS differ), and the lowest in SV replacives (where the CC and the AS coincide). In disjunctions (where there is no AS), 3rd person bias falls between the two replacive conditions. These findings suggest that when the grammar encounters conflicting information or has to choose between satisfying multiple dependencies, it prefers less featurally marked forms.

\footnotetext{
2 Past tense 3rd person forms containing a medial stop followed by [i] generally undergo the deletion of [i] when the 1st person suffix [-in] is added, however there are lexical exceptions, such as vettisin (*vetsin), 'I got soaked', making the phonological process not fully predictable.
} 


\begin{tabular}{ccc} 
& Disjunction & Replacives \\
\hline SV & $8.10(2.46)$ & $2.77(2.84)$ \\
VS & $\underline{14.33} \underline{(2.31)}$ & $\underline{22.48}(2.19)$
\end{tabular}

Table 4. Means (and SE) for 3rd person bias in Experiment 3. Max bias $=50$

The 3rd person bias scores were modeled in lmer models in $\mathrm{R}$, crossing the fixed effects of Construction, Word order and Verb form, adding random intercepts for participants and items. There were no significant effects or interactions with Verb form, suggesting that at least in the present subtle morphophonological manipulation, the surface form of the verb did not influence agreement preferences. There was, however, a main effect of Word order, whereby verbs in VS clauses showed a higher 3rd person bias $(M=18.40, S E=1.60)$ than verbs in $\mathrm{SV}$ clauses $(\mathrm{M}=5.44, \mathrm{SE}=1.88), p<.05$. This effect seems to be partially driven by the high 3rd person bias in VS replacives, as seen in Table 4, which is supported by there being a significant interaction between Construction and Word order $(p<.05)$, however the higher bias for 3rd person verbs in VS disjunctions compared to SV disjunctions is also interesting. One possibility is that there are more conflicting biases in VS constructions than SV constructions overall, as the clause-final placement of subjects could make the second conjunct more (prosodically) salient in a language with a clause-final focus position. The more salient second conjunct could be competing for agreement marking on the verb with the first conjunct, which is a CC, leading to additional factors such as feature markedness having to be considered by the grammar.

Moving on to CCA bias, Figure 4 plots bias towards agreeing with the $\mathrm{CC}$ as a function of experimental condition and the person of the $\mathrm{CC}$ (which was varied between items).

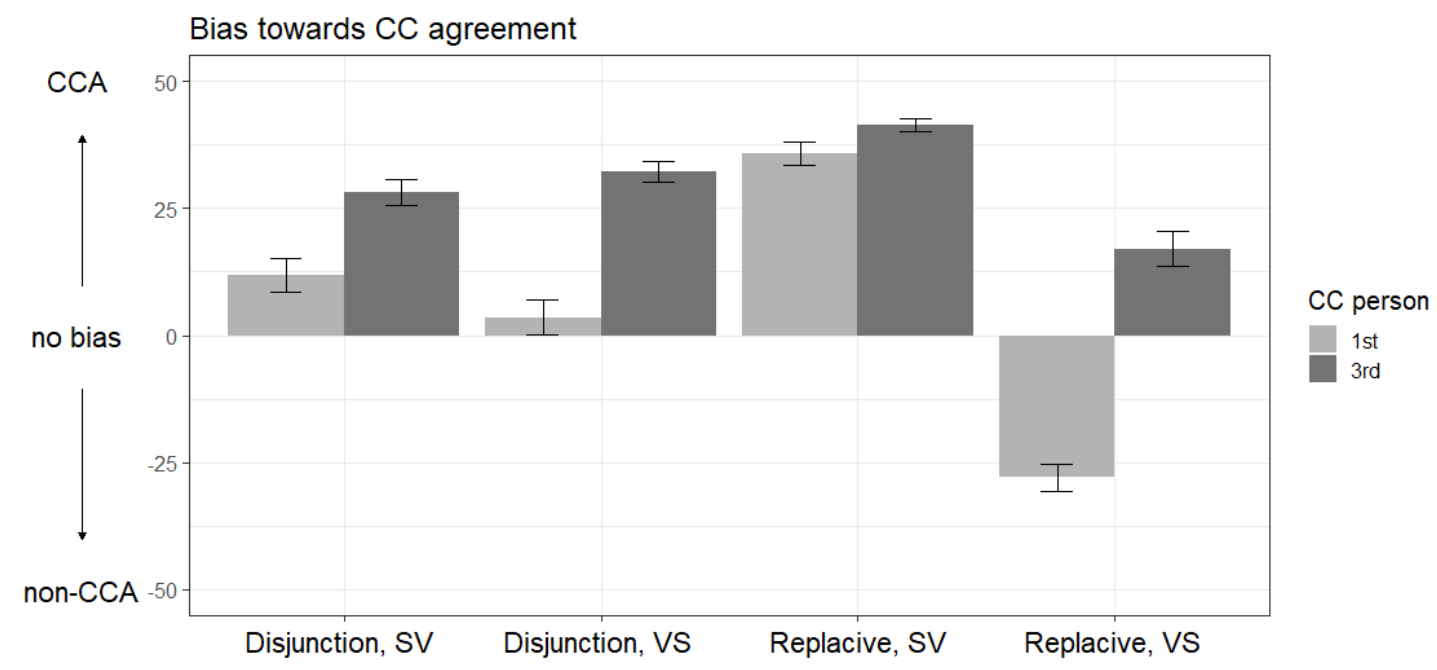

Figure 4. CCA bias in Experiment 3, depending on the person-marking of the $\mathrm{CC}$

The data were modeled using lmer models in R, crossing the fixed effects of Construction, Word order and CC person, adding random intercepts for participants and items. A significant intercept $(p<.001)$ confirms an overall CCA bias, which is further increased for replacives $(p<.001)$ and SV clauses $(p<.05)$. The latter two main effects appear to be driven by high 
rates of CCA specifically in SV replacives, where CCA and ASA coincide, and accordigly, we see a significant interaction between Construction and Word order $(p<.001)$. There is also an effect of CC person, with 3rd person CCs $(\mathrm{M}=29.67, \mathrm{SE}=1.28)$ being significantly more biasing towards CCA than 1st person $\mathrm{CCs}(\mathrm{M}=5.83, \mathrm{SE}=1.82), p<.001$. CC person also significantly interacts with Word order, by being a stronger determinant of CCA in postverbal subjects $(p<.05)$. Further, there is a three-way interaction between Construction, Word order and CC person $(p<.001)$, suggesting that CC person affected CCA bias differently in the four experimental conditions. The full model output is shown in Table 5. Pairwise t-tests using the emmeans package in $\mathrm{R}$ (with tukey adjustments to $p$ values) revealed significant $\mathrm{CC}$ person effects in all conditions except SV replacives $(p s<.01)$.

\begin{tabular}{|lllllll|}
\hline & Estimate & $\mathrm{SE}$ & $\mathrm{df}$ & $\mathrm{t}$ value & $\operatorname{Pr}(>|\mathrm{t}|)$ & \\
(Intercept) & 12.103 & 2.983 & 302.396 & 4.057 & $6.33 \mathrm{e}-05$ & $* * *$ \\
Wonstr.Rep & 23.527 & 3.713 & 927.219 & 6.337 & $3.66 \mathrm{e}-10$ & $* * *$ \\
PO.VS & -8.450 & 3.694 & 920.567 & -2.287 & 0.022394 & $*$ \\
Conson.3 & 15.835 & 3.713 & 927.219 & 4.265 & $2.20 \mathrm{e}-05$ & $* * *$ \\
Constr.Rep:WO.VS & -55.241 & 5.251 & 927.219 & -10.520 & $<2 \mathrm{e}-16$ & $* * *$ \\
WO.VS:Person.3 & -9.929 & 5.303 & 938.006 & -1.872 & 0.061500 & \\
Constr.Rep:WO.VS:Person.3 & 12.601 & 5.251 & 927.219 & 2.400 & 0.016604 & $*$ \\
& 26.674 & 7.500 & 938.006 & 3.556 & 0.000395 & $* * *$ \\
\hline
\end{tabular}

Table 5. Output of lmer model for CCA bias. Statistically significant effects marked with "*”, trending effects with ".".

In Figure 4, we see an overall bias for CCA, with a few notable exceptions, and varying influence of CC person (i.e. featural markedness of the resulting verbal form). As we saw in Table 4, there is a stronger 3rd person verb preference in VS disjunctions than SV disjunctions, which explains the differences in CCA bias by CC person in the disjunction conditions here. Interestingly, an overall CCA bias was seen in all disjunction conditions with the exception of VS disjunction with a 1st person $\mathrm{CC}(\mathrm{M}=3.54, \mathrm{SE}=3.50)$, repeated in (6). A look at byparticipant responses for this subset of the data reveals great variability, much like reported by Marušič et al. (2015) for Slovenian, rather than consistent center-of-scale responses - 32.5\% of participants never provided a CCA response (i.e. $>0$ ) while $25 \%$ of participants only provided CCA responses in this condition.

\begin{tabular}{|c|c|c|c|c|c|}
\hline $\begin{array}{l}\text { Raamatuid } \\
\text { books }\end{array}$ & $\begin{array}{l}\text { ?lugesin/?luges } \\
\text { read.?1SG/?3SG yesterday }\end{array}$ & $\begin{array}{ll}\text { hommikul } & \text { kas } \\
\text { morning } & \text { either }\end{array}$ & $\begin{array}{l}\operatorname{mina} \\
\mathrm{I}\end{array}$ & $\begin{array}{l}\text { või } \\
\text { or }\end{array}$ & $\begin{array}{l}\text { Anna } \\
\text { Anna }\end{array}$ \\
\hline
\end{tabular}

VS replacives, the condition of highest interest in the context of Exp 1 and Exp 2, show an interesting pattern of results, driven by a high bias for 3rd person verb forms. In contrast with Exp 2, we actually see a slight overall AS bias in this condition $(\mathrm{M}=-5.47, \mathrm{SE}=2.60)$. There was considerable inter-participant variation in this condition as well. $12.5 \%$ of the participants always displayed an ASA bias, regardless of CC person. No participants consistently showed CCA bias, which would have involved ignoring the person-marking of the non-CC constituent. $37.5 \%$ always showed 3rd person bias, regardless of whether the 3rd person subject was CC or AS. 
Despite the increased ASA effect in this offline, untimed experiment, a comparison between SV replacives with 3rd person CCs and VS replacives with 1st person CCs reveals that CCA still plays a role in speakers' judgments. Namely, in the SV replacives, the magnitude of CCA bias when CC, AS and 3rd person agreement coincide is $\mathrm{M}=41.35$ ( $\mathrm{SE}=1.34$ ), but the magnitude of CCA bias in VS replacives where the non-CCA agreement form is only supported by ASA and 3rd person bias is smaller, $\mathrm{M}=-27.95$ ( $\mathrm{SE}=2.68$ ). At the same time, the higher CCA bias in SV replacives compared to SV disjunctions confirms the effect of ASA in coordination structures, as does the overall reduction in CCA bias in VS replacives compared to VS disjunctions.

Overall, Exp 3 showed that agreement patterns in coordination are influenced by CCA, ASA, as well as featural markedness, with some evidence of variability in how speakers rank these different grammatical constraints.

5. General discussion. To summarize the present findings, Exp 1 showed that postverbal replacives with mismatching subject features produce diminished acceptability in Estonian, but that person mismatches are fully repaired by morphological syncretism (here, negative concord). Exp 2 provided evidence for CCA in replacive subject coordination, as well as featural markedness effects, whereby [-speaker, -participant] 3rd person verbal forms improve acceptability over more marked [+speaker, +participant] 1st person verbal forms. The effects of featural markedness on agreement preferences were replicated using a different experimental paradigm in Exp 3. Additionally, Exp 3 pointed to both closest conjunct agreement (CCA) and asserted subject agreement (ASA) being relevant to determining verbal agreement with coordinated subjects of mismatching person features.

The results of Exp 2 and Exp 3 do not completely align though. In Exp 2, postverbal replacives with ASA were accepted on only $25 \%$ of trials, however in Exp 3, there was actually a slight preference overall for ASA verb forms in postverbal replacives. As mentioned, the diminished effect of interpretations (i.e. asserted subjects) on grammaticality in the speeded acceptability task in Exp 2 could have arisen from the time pressure of the task. However, another possibility arises from slight differences in experimental materials. In Exp 1 and Exp 2, a comma was used to separate the two conjuncts ("not X, but Y"), following prescriptive punctuation rules of Estonian. In Exp 3, the comma was omitted in order to make the replacives and disjunctives more parallel. A higher CCA preference in Exp 2 compared to Exp 3 could have arisen from this difference. Namelu, previous psycholinguistic work has shown punctuation to trigger wrap-up effects (Hirotani et al. 2006), encouraging the language processor to resolve any outstanding dependencies. This could have lead readers in Exp 2 to compute an agreement relation between the verb and the comma-preceding CC. Moreover, the inclusion of the comma in Exp 2 could have biased readers towards a biclausal structure, in which case it is not surprising to see the overt verb agree with the local subject (CC). This effect could have been further amplified by the inclusion of the biclausal (Double Verb) baseline condition in Exp 2. Nonetheless, a comparison with preverbal replacives in Exp 3 showed that CCA plays a role in replacives even in the absence of biasing punctuation.

Further work is needed to explore the possibility of replacive coordination structures being ambiguous between constituent coordination and clausal coordination with ellipsis, and how the computed syntactic structure contributes to the relative influence of CCA, ASA and featural markedness in determining verbal agreement. This is particularly interesting given that 
speakers receive impoverished input when it comes to postverbal replacives in Estonian - Exp 1 showed that negative concord offers a perfectly grammatical paraphrase when two subjects in a replacive construction differ in their person features.

Another interesting question to address is whether the 3rd person verb preference observed in Exp 2 and Exp 3 amounts to default agreement or resolved agreement (with independent grammatical constraints ruling out the use of a plural form in replacives). Here, a vital test case would be replacive constructions with 3rd person singular and 3rd person plural conjuncts. Under the default agreement hypothesis, we might expect to see a preference for the less marked, [-plural] form. Under the resolved agreement hypothesis, where the verb agrees with the features of the coordination as a whole (Bhatt \& Walkow 2013), the [+plural] form would be expected to be preferred.

With judgments of acceptability for agreement mismatches being subtle and variable, psycholinguistic methods are likely to continue to provide valuable insight to understanding this fascinating phenomenon.

\section{References}

Bhatt, Rajesh \& Martin Walkow. 2011. Asymmetries in conjunct agreement. University of Pennsylvania Working Papers in Linguistics 17(1). 3.

Bhatt, Rajesh \& Martin Walkow. 2013. Locating agreement in grammar: An argument from agreement in conjunctions. Natural Language \& Linguistic Theory 31(4). 951-1013. https://doi.org/10.1007/s11049-013-9203-y.

Coon, Jessica, Stefan Keine \& Michael Wagner. 2017. Hierarchy effects in copular constructions: The pcc corner of german. In Andrew Lamont \& Katerina Tetzloff (eds.), Proceedings of NELS 47. 205-214. Amherst, MA: GLSA.

Corbett, Greville G. 1983. Hierarchies, targets and controllers: Agreement patterns in Slavic. Croom Helm London.

Drummond, Alex. 2013. Ibex farm. Online server: http://spellout.net/ibexfarm.

Fehrmann, Dorothee. 2008. The syntax of contrast and correction readings of Polish adversative coordinate structures. In Anita Steube (ed.), The discourse potential of underspecified structures. 321-358. Berlin: De Gruyter. https://doi.org/10.1515/9783110209303.4.321.

Foppolo, Francesca \& Adrian Staub. 2020. The puzzle of number agreement with disjunction. Cognition 198. 104161. https://doi.org/10.1016/j.cognition.2019.104161.

Henk, Paula. 2010. Information structure of Estonian - compared to Finnish and Hungarian. Osnarbrük: Publications of the Institute of Cognitive Science.

Hirotani, Masako, Lyn Frazier \& Keith Rayner. 2006. Punctuation and intonation effects on clause and sentence wrap-up: Evidence from eye movements. Journal of Memory and Language 54(3). 425-443. https://doi.org/10.1016/j.jml.2005.12.001.

Koutsoudas, Andreas. 1968. A-over-A convention. Linguistics (46). 11-20.

Marušič, Franc, Andrew Ira Nevins \& William Badecker. 2015. The grammars of conjunction agreement in slovenian. Syntax 18(1). 39-77. https://doi.org/10.1111/synt.12025.

Nevins, Andrew \& Philipp Weisser. 2019. Closest conjunct agreement. Annual Review of Linguistics 5. 219-241. https://doi.org/10.1146/annurev-linguistics-011718-012708.

Pullum, Geoffrey K. \& Arnold M Zwicky. 1986. Phonological resolution of syntactic feature conflict. Language 62(4). 751-773. https://www.jstor.org/stable/415171.

Rohde, Doug. 2003. Linger: A flexible platform for language processing experiments.

Team, R Core. 2013. R: A language and environment for statistical computing. 